\title{
Pengendalian Korosi Menggunakan Inhibitor Kitosan Larut Air untuk Baja Lunak dalam Media $\mathrm{HCl} 1 \mathrm{M}$
}

\author{
Clarissa Welny Saleh, Harmami, dan Ita Ulfin \\ Jurusan Kimia, Fakultas Matematika dan Ilmu Alam, Institut Teknologi Sepuluh Nopember (ITS) \\ Jl. Arief Rahman Hakim, Surabaya 60111 Indonesia \\ e-mail: harmami@chem.its.ac.id
}

\begin{abstract}
Abstrak-Kitosan larut air (Water Soluble Chitosan, WSC) berhasil disintesis dari limbah cangkang udang dan dimanfaatkan sebagai inhibitor korosi. Limbah cangkang udang didemineralisasi dan dideproteinisasi untuk memperoleh kitin. WSC diperoleh dari proses deasetilasi kitin dan pemotongan rantai kitosan kasar dengan $\mathrm{H}_{2} \mathrm{O}_{2}$. WSC dikarakterisasi dengan FT-IR dan ditentukan derajat deasetilasinya dengan titrasi asam basa. Kinerja WSC dalam menghambat korosi baja lunak $\mathrm{HCl} 1 \mathrm{M}$ telah dipelajari dengan metode polarisasi potensiodinamik. Studi efisiensi inhibisi WSC dilakukan pada variasi konsentrasi 25-175ppm dalam media korosif pada kondisi stagnan dan dengan pengadukan. Hasil yang diperoleh menunjukkan efisiensi inhibisi WSC meningkat terhadap konsentrasi dan mencapai maksimum pada konsentrasi $100 \mathrm{ppm}$. Efisiensi maksimum WSC diperoleh sebesar $\mathbf{7 3 , 5 0 \%}$. Intepretasi hasil pengukuran dengan polarisasi potensiodinamik menunjukkan bahwa WSC merupakan inhibitor tipe campuran. Adsorpsi WSC pada permukaan baja lunak dalam HCl 1M mengikuti model isotermal adsorpsi Freundlich.
\end{abstract}

Kata Kunci-Inhibitor; Kitosan; Korosi; Polarisasi Potensiodinamik.

\section{PENDAHULUAN}

$\mathrm{B}$ AJA lunak (mild steel) merupakan paduan (alloy) karbon dan besi dengan kandungan karbon sebesar $0,05-0,30 \%$ sehingga baja lunak memiliki sifat yang ulet dan mudah ditempa [1]. Baja lunak digunakan hampir di seluruh sektor industri karena sifat dan harganya yang murah. Baja lunak umumnya digunakan sebagai material konstruksi pada kilang minyak, pabrik makanan, pembangkit listrik dan industri kimia. Baja lunak memiliki kekurangan yaitu sangat sensitif terhadap asam sehingga terjadi korosi pada baja lunak [2]. Korosi dapat didefinisikan sebagai suatu proses yang dialami oleh logam yang telah dimurnikan dimana logam tersebut mengalami perubahan secara reaksi elektrokimia antara logam dan lingkungannya menjadi bentuk logam yang lebih stabil yaitu oksida logam, hidroksida logam atau ion logam yang larut [3]. Korosi menjadi salah satu masalah utama dalam industri yang menimbulkan kerugian sangat besar. Kerugian yang diakibatkan oleh korosi seperti kegagalan pada material, kerusakan pada peralatan hingga kegagalan pada sistem operasi, menimbulkan dampak ekonomi yang cukup besar. Di negara maju seperti Amerika Serikat, kerugian yang diakibatkan oleh korosi di sektor industri mencapai US\$ 276 juta per tahun. Pengendalian korosi pada baja lunak yang telah dikembangkan diantaranya perlindungan anodik menggunakan anoda tumbal yaitu logam seng
$(\mathrm{Zn})$, perlindungan katodik menggunakan epoksi sebagai bahan pelapis baja lunak dan penggunaan inhibitor korosi [4].

Metode pengendalian korosi dengan inhibitor korosi merupakan salah satu metode yang umum dan berkembang sangat pesat. Pengendalian korosi menggunakan inhibitor mampu memperpanjang umur penggunaan logam atau alloy [5]. Senyawa dikromat, nitrat dan beberapa polimer umum digunakan sebagai inhibitor korosi untuk berbagai jenis logam dan alloy dalam beberapa media [6]. Penggunaan senyawa anorganik, senyawa organik dan polimer sintetik memiliki dampak yang tidak ramah terhadap lingkungan sehingga aplikasinya menjadi sangat terbatas [7]. Penelitian dan pengembangan inhibitor yang ramah lingkungan telah dilakukan dengan menggunakan ekstrak tanaman, minyak nabati, sari buah dan limbah sebagai bahan baku green inhibitor. Biopolimer menjadi salah satu green inhibitor yang lebih diminati karena sifatnya yang baik dalam perlindungan korosi pada beberapa lokasi adsorpsi. Beberapa contoh biopolimer yang digunakan sebagai green inhibitor diantaranya adalah kinina [8], [9], lignin dan karboksimetil kitosan [10].

Kitosan merupakan produk hasil $\mathrm{N}$-deasetilasi dari kitin. Kitin sebagai bahan baku kitosan merupakan polisakarida asetilamina yang banyak ditemukan pada cangkang udang, kerang dan kepiting. Baik kitin maupun kitosan bersifat biodegradable dan tidak beracun [11]. Kitosan memiliki gugus hidroksil (-OH) dan gugus amina $\left(-\mathrm{NH}_{2}\right)$ yang dapat berikatan secara elektrostatik maupun secara kovalen koordinasi dengan Fe pada baja lunak [12]. Beberapa penelitian terdahulu memanfaatkan turunan kitosan sebagai inhibitor korosi dan pelapis untuk baja lunak. Kitosan dan turunannya yang telah dimanfaatkan sebagai inhibitor korosi untuk baja lunak diantaranya kitosan [13], surfaktan kitosan [14], kitosan/nanopratikel $\mathrm{ZnO}$ [15], karboksimetil kitosan [16], kitosan-g-PEG/Nanopartikel Ag [17] dan asetil tiourea kitosan [18]. Pada penelitian ini digunakan kitosan larut air (WSC) yang diperoleh dari limbah cangkang kulit udang sebagai inhibitor korosi untuk baja lunak dalam media $\mathrm{HCl} 1 \mathrm{M}$. Kinerja WSC sebagai inhibitor korosi dievaluasi dengan metode polarisasi potensiodinamik. Studi termodinamika dan isotermal adsorpsi WSC dipelajari untuk menentukan mekanisme penghambatan korosi baja lunak dalam $\mathrm{HCl} 1 \mathrm{M}$. 


\section{METODOLOGI PENELITIAN}

\section{A. Peralatan dan bahan}

Peralatan yang digunakan dalam penelitian ini adalah kertas amplas grit 500, 800 dan 1000, peralatan gelas, neraca analitik digital Ohaus PA512 (maksimum 510g \pm $0.01 \mathrm{~g}$ ), oven Thermoscientific FREAS 650, sonikator ultrasonic cleaner PS-20, instrument analisis elektrokimia Autolab PGSTAT128N dengan software Nova 1.11 dan spektrometer inframerah Shimadzu FT-IR 8400S. Bahan yang digunakan dalam penelitian ini adalah limbah cangkang udang dari pasar tempurejo Surabaya, baja lunak karbon rendah (dengan komposisi $\mathrm{C}=0,0096 ; \mathrm{Si}=0,062 ; \mathrm{Mn}=1,499 ; \mathrm{S}=0,014 ; \mathrm{Cr}=$ $0.015 ; \mathrm{P}=0,013 ; \mathrm{Cu}=0,033 ; \mathrm{Fe}=98,268)$, cat pelapis tahan air, aquademin, aseton (Merck, 99,9\%), HCl pekat (Merck, 37\%), etanol absolut (Merck, 99,9\%), $\mathrm{NaOH}$ pelet (Merck, 99,9\%), $\mathrm{CH}_{3} \mathrm{COOH}$ glasial (Merck, 100\%), dan $\mathrm{H}_{2} \mathrm{O}_{2}$ (Merck, 30\%).

\section{B. Prosedur Percobaan}

\section{1) Sintesis Kitosan Larut Air (WSC)}

Limbah cangkang udang yang diperoleh dari pasar tempurejo Surabaya dikeringkan dan dihaluskan. Serbuk cangkang udang halus sebanyak $50 \mathrm{~g}$ direndam dalam $500 \mathrm{~mL} \mathrm{HCl} 7 \%$ selama 24 jam dan disaring. Residu cangkang udang direndam dengan $500 \mathrm{~mL} \mathrm{NaOH} 10 \%$ selama 24 jam pada suhu $60^{\circ} \mathrm{C}$. Kitin hasil demineralisasi dan deproteinisasi dibilas dengan $125 \mathrm{~mL}$ etanol absolut dan dikeringkan dengan oven pada suhu $50^{\circ} \mathrm{C}$ selama 10 jam. Ekstrak kitin direndam dalam $\mathrm{NaOH} \quad 50 \%$ (perbandingan bobot kitin: volume $\mathrm{NaOH}, 1: 2$ ) selama 8 jam pada suhu $60^{\circ} \mathrm{C}$. Residu yang berupa kitosan kasar disaring dan dikeringkan dalam oven pada suhu $50^{\circ} \mathrm{C}$ selama 10 jam. Kitosan kasar kering dilarutkan dalam asam asetat $2 \%$ dengan perbandingan bobot kitosan kasar: volume asam asetat, 1:20). $\mathrm{H}_{2} \mathrm{O}_{2} 30 \%$ ditambahkan (bobot kitosan kasar: volume $\mathrm{H}_{2} \mathrm{O}_{2} 30 \%, 1: 4$ ) ke dalam larutan kitosan dan direaksikan pada suhu $40^{\circ} \mathrm{C}$. Larutan kitosan larut air kemudian disaring. Etanol 96\% ditambahkan ke dalam filtrate sebanyak 2 kali volume filtrat. Etanol diuapkan dalam oven suhu $50^{\circ} \mathrm{C}$. Padatan kitin dan kitosan larut air yang diperoleh kemudian dikarakterisasi dengan spektrofotometer FT-IR untuk mengetahui gugus fungsi dalam kitin dan kitosan larut air [19].

2) Pengujian Efisiensi Inhibisi WSC dengan Metode Polarisasi Potensiodinamik

Pengujian dengan elektrokimia menggunakan tiga elektroda yang dirangkaikan pada temperatur kamar. Elektroda baja lunak dengan luas permukaan kontak yaitu $1 \mathrm{~cm}^{2}$ digunakan sebagai elektroda kerja. Kawat platinum digunakan sebagai elektroda bantu dan elektroda $\mathrm{Ag} / \mathrm{AgCl} \quad(\mathrm{KCl} 3 \mathrm{M})$ sebagai elektroda pembanding. Spesimen baja lunak direndam selama 15 menit dalam media $\mathrm{HCl} 1 \mathrm{M}$ blanko dan dengan variasi konsentrasi inhibitor (25-75ppm WSC dalam $\mathrm{HCl} 1 \mathrm{M})$. Pengujian dilakukan dengan menggunakan potensial sebesar $-300 \mathrm{mV}$ hingga $+300 \mathrm{mV}$ dan laju $1 \mathrm{mVs}^{-1}$ pada potensial rangkaian terbuka. Pengukuran dilakukan dengan pada temperatur ruang $\left(25^{\circ} \mathrm{C}\right)$. Ekstrapolasi dilakukan pada grafik Tafel untuk memperoleh nilai potensial korosi $\left(E_{\text {corr }}\right)$ yang kemudian didapatkan pula densitas arus korosi $\left(I_{\text {corr }}\right)$, konstanta Tafel anodik dan katodik $\left(\beta_{a}\right.$ dan $\left.\beta_{c}\right)$. Data $I_{c o r r}$ kemudian digunakan untuk menghitung efisiensi penghambatan ( $\%$ EI) dengan persamaan (1).

$\% \mathrm{EI}=\frac{\mathrm{i}_{\mathrm{CORR}}-\mathrm{i}_{\mathrm{CORR}}}{\mathrm{i}_{\mathrm{CORR}}} \times 100 \%$

pada persamaan $1, i_{C O R R}$ merupakan nilai densitas arus korosi tanpa inhibitor sedangkan $i^{\prime}{ }_{\text {CORR }}$ merupakan nilai densitas arus korosi dengan inhibitor.

\section{HASIL DAN DISKUSI}

Pada penelitian ini digunakan kitosan larut air (Water Soluble Chitosan, WSC) sebagai inhibitor untuk baja lunak dalam $\mathrm{HCl} 1 \mathrm{M}$. Prosedur sintesis WSC didasarkan pada penelitian Du dkk., (2009), dimana kitin dalam cangkang udang diekstraksi melalui tahapan demineralisasi dan deproteinisasi kemudian kitin direaksikan dengan $\mathrm{NaOH}$ untuk menghasilkan kitosan kasar (tahap deasetilasi). Kitosan kasar yang diperoleh kemudian direaksikan dengan $\mathrm{H}_{2} \mathrm{O}_{2}$ untuk menghasilkan WSC. Reaksi yang berlangsung seperti pada Gambar 1.

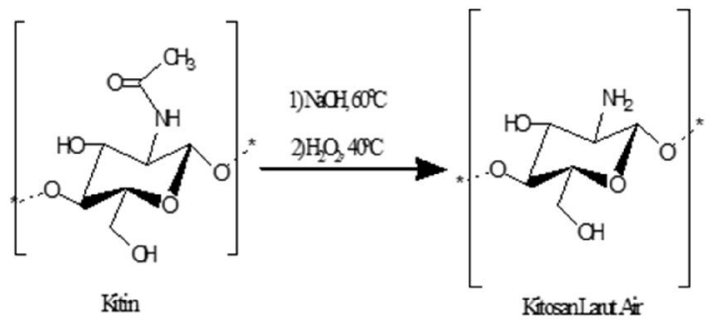

Gambar 1. Reaksi Sintesis Kitosan Larut Air (WSC)

Hasil karakterisasi kitin dan WSC dengan spektrofotometer FT-IR menghasilkan spektra IR kitin dan WSC (Gambar 4.3). Pada spektra kitin terlihat puncak-puncak spesifik yang menunjukkan gugus fungsi pada kitin yaitu pada $3449 \mathrm{~cm}^{-1}$ yang menunjukkan vibrasi ulur $-\mathrm{OH}$. Puncak pada $2924 \mathrm{~cm}^{-1}$ menunujukkan vibrasi $\mathrm{C}-\mathrm{H} \mathrm{sp}^{3}$. Puncak pada $1658 \mathrm{~cm}^{-1}$ menunjukkan vibrasi $\mathrm{C}=\mathrm{O}$ amida sedangkan puncak pada $1553 \mathrm{~cm}^{-1}$ dan $1381 \mathrm{~cm}^{-1}$ menunjukkan vibrasi N-H amida. Puncak pada $1074 \mathrm{~cm}^{-1}$ dan $1026 \mathrm{~cm}^{-1}$ menunjukkan vibrasi ikatan C-O-C. Pada spektra WSC terlihat puncakpuncak spesifik yang mirip dengan puncak yang muncul pada spektra kitin yaitu puncak pada $3416 \mathrm{~cm}^{-1}$ menunjukkan vibrasi O-H, puncak pada $1631 \mathrm{~cm}^{-1}$ menunjukkan vibrasi amina primer dan puncak pada $1070 \mathrm{~cm}^{-1}$ dan $1031 \mathrm{~cm}^{-1}$ menujukkan vibrasi C-O-C. Berbeda dengan spektra IR kitin, pada spektra IR WSC tidak terdapat serapan pada $3263 ; 3103 ; 1658 ; 1553$ dan $1381 \mathrm{~cm}^{-1}$ karena gugus amida yang telah hilang akibat reaksi deasetilasi selain itu, puncak pada $1408 \mathrm{~cm}^{-1}$ muncul yang merupakan puncak formasi vibrasi $\mathrm{N}-\mathrm{H}$ primer.

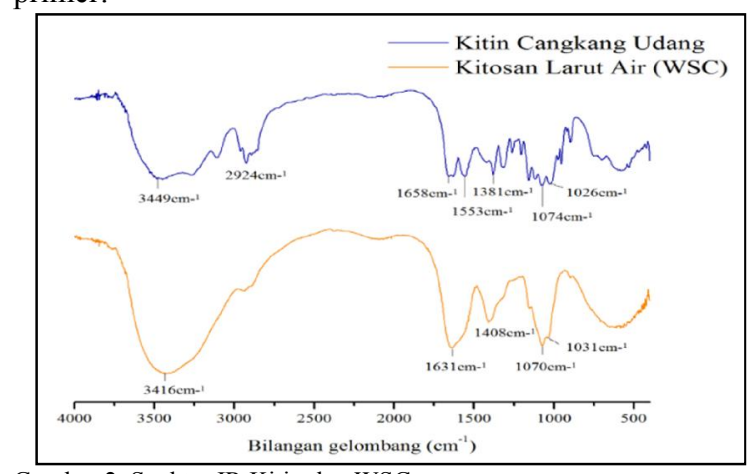

Gambar 2. Spektra IR Kitin dan WSC 
Perbandingan antara spektra IR kitin dan WSC membuktikan bahwa reaksi deasetilasi kitin berhasil dan menghasilkan kitosan (WSC) [20].

\section{A. Studi Polarisasi Potensiodinamik}

Pengukuran polarisasi potensiodinamik dilakukan untuk menentukan efisiensi inhibisi dan sifat proteksi WSC di permukaan baja lunak dengan $\mathrm{HCl} 1 \mathrm{M}$. Hasil pengukuran polarisasi potensiodinamik berupa grafik Tafel untuk baja lunak dalam media korosif petroleum sintetik dan $\mathrm{HCl} 1 \mathrm{M}$ ditunjukkan pada Gambar 3.

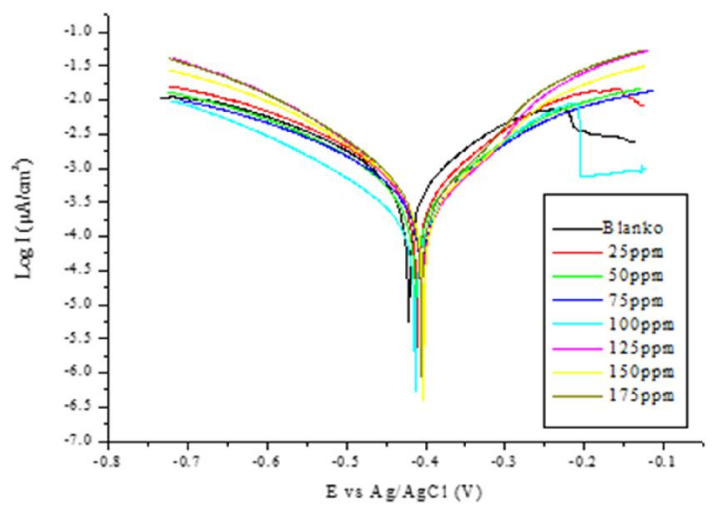

Gambar 3. Grafik tafel baja lunak dalam media $\mathrm{HCl} 1 \mathrm{M}$ dengan variasi konsentrasi inhibitor WSC.

Pada grafik Tafel yang ditunjukkan pada Gambar 3, kurva polarisasi katodik menunjukkan bahwa WSC bekerja menghambat korosi dengan menutup atau memblokir seluruh sisi aktif baja lunak tanpa memodifikasi reaksi katodik (reduksi ion $\mathrm{H}^{+}$). Ekstrapolasi Tafel dilakukan pada masing-masing kurva polarisasi sehingga didapatkan data parameter polarisasi dan efisiensi inhibisi WSC yang dihitung dengan persamaan 2. Hasil ekstrapolasi Tafel serta perhitungan efisiensi inhibisi WSC ditampilkan dalam Tabel 1.

Tabel 1 .

Data parameter polarisasi dan efisiensi WSC untuk

\begin{tabular}{cccccc}
\hline \hline $\begin{array}{c}\mathbf{C}_{\text {wsc }} \\
(\mathbf{p p m})\end{array}$ & $\begin{array}{c}\boldsymbol{\beta}_{\mathrm{a}} \\
(\mathbf{m V} / \mathbf{d e c})\end{array}$ & $\begin{array}{c}\boldsymbol{\beta}_{\mathbf{c}} \\
(\mathbf{m V} / \mathbf{d e c})\end{array}$ & $\begin{array}{c}\boldsymbol{E}_{\text {corr }} \\
(\mathbf{m V})\end{array}$ & $\begin{array}{c}\boldsymbol{I}_{\text {corr }} \\
\left(\boldsymbol{\mu} \mathbf{A} / \mathbf{c m}^{2}\right)\end{array}$ & $\mathbf{E I ~ ( \% )}$ \\
\hline Blanko & 169,77 & 160,28 & $-421,97$ & 700,110 & - \\
\hline 25 & 131,23 & 136,29 & $-410,67$ & 502,030 & 27,86 \\
\hline 50 & 143,70 & 158,68 & $-410,69$ & 431,630 & 37,98 \\
75 & 123,73 & 127,41 & $-408,88$ & 394,500 & 43,31 \\
100 & 168,84 & 106,04 & $-413,89$ & 184,430 & 73,50 \\
125 & 105,70 & 137,67 & $-403,55$ & 332,840 & 52,17 \\
150 & 148,95 & 147,12 & $-403,12$ & 413,360 & 40,60 \\
\hline 175 & 134,02 & 159,99 & $-403,48$ & 477,590 & 31,37 \\
\hline \hline
\end{tabular}

Penentuan tipe proteksi anodik atau katodik dari suatu inhibitor korosi dapat dilihat dari nilai $E_{\text {corr }}$ pengukuran jika terjadi perubahan $E_{\text {corr }}$ lebih dari $85 \mathrm{mV}$ dari nilai $E_{\text {corr }}$ blanko (tanpa penggunaan inhibitor) ke arah potensial anodik atau katodik. Dari keseluruhan data yang diperoleh dapat dilihat bahwa perubahan nilai $E_{\text {corr }}$ dengan menggunakan inhibitor berubah terhadap nilai $E_{\text {corr }}$ tanpa inhibitor dengan perubahan rata-rata berada di bawah $85 \mathrm{mV}$ maka dapat diketahui bahwa tipe proteksi WSC pada baja lunak adalah proteksi campuran anodik dan katodik [21]. Nilai $\beta$ a berhubungan dengan disolusi logam $\mathrm{Fe}$ pada permukaan baja lunak pada potensial anodik dan $\beta \mathrm{c}$ berhubungan dengan pembentukan gas hidrogen $\left(\mathrm{H}_{2}\right)$ pada potensial katodik. Data $\beta \mathrm{a}$ dan $\beta \mathrm{c}$ dengan adanya inhibitor WSC mengalami perubahan terhadap blanko. Pola perubahan nilai $\beta \mathrm{a}$ dan $\beta \mathrm{c}$ tidak berpengaruh terhadap konsentrasi WSC. Perubahan nilai $\beta a$ dan $\beta c$ menunjukkan bahwa WSC melindungi di bagian anoda maupun katoda pada permukaan baja lunak [22].

Data $I_{\text {corr }}$ menunjukkan adanya penurunan seiring naiknya konsentrasi inhibitor hingga pada konsentrasi $100 \mathrm{ppm}$. $I_{\text {corr }}$ mengalami kenaikan setelah konsentrasi 100ppm, hal ini diakibatkan oleh adanya aktivitas inhibisi oleh WSC pada baja lunak melalui mekanisme adsorpsi fisik WSC pada permukaan baja lunak. Adsorpsi fisik yang terjadi merupakan ikatan yang lemah antara inhibitor dan Fe dalam baja lunak [23]. Hal ini menyebabkan pada konsentrasi tinggi (>100ppm) inhibitor lepas dan berdifusi ke larutan. Kecenderungan efisiensi inhibisi WSC menunjukkan kenaikan seiring naiknya konsentrasi inhibitor hingga $100 \mathrm{ppm}$. Efisiensi inhibisi mengalami penurunan setelah konsentrasi 100ppm.

\section{B. Isotermal Adsorpsi dan Studi Termodinamika Korosi}

Mekanisme penghambatan korosi oleh WSC dapat dipelajari dengan mengetahui model isotermal adsorpsi WSC pada permukaan baja lunak. Plot grafik hubungan konsentrasi inhibitor $\left(C_{i n h}\right)$ dan cakupan permukaan $(\theta)$ WSC pada baja lunak dalam media $\mathrm{HCl} 1 \mathrm{M}$ dilakukan menggunakan bebebrapa persamaan model isotermal adsorpsi (Langmuir, Freundlich, Frumkin, dan Temkin). Hasil plot grafik linear menunjukkan bahwa adsorpsi WSC pada permukaan baja lunak mengikuti model isotermal Freundlich. Hal ini terlihat dari nilai koefisien regresi $\left(\mathrm{R}^{2}\right)$ dengan persamaan isotermal Freundlich adalah $0,884\left(\mathrm{R}^{2} \approx 1\right)$.

Adsorpsi WSC mengikuti model isotermal adsorpsi Freundlich, hal ini menunjukkan adanya interaksi antara molekul inhibitor dan besi dalam baja lunak. Selain itu model isotermal adsorpsi ini menunjukkan pula adanya interaksi antara molekul inhibitor yang teradsorpsi dan molekul inhibitor yang berada di larutan. Oleh karena itu, efisiensi inhibisi korosi WSC pada baja lunak turun setelah konsentrasi optimum. Penurunan efisiensi inhibisi ini disebabkan adanya difusi inhibitor ke larutan [24].

Nilai $K$ dalam persamaan isotermal adsorpsi merupakan konstanta adsorpsi-desorpsi $\left(K_{a d s}\right)$ yang diperoleh dari perhitungan nilai intersep pada persamaan linier grafik isotermal adsorpsi. Nilai energi bebas Gibbs adsorpsi $\Delta G_{a d s}^{\circ}$ berhubungan dengan nilai $K_{a d s}$ yang diperoleh dari persamaan linier isotermal adsorpsi dan dapat dihitung dengan persamaan 2 .

$\mathrm{K}_{\mathrm{ads}}=\frac{1}{1000} \exp \left[\frac{-\Delta \mathrm{G}_{\mathrm{ads}}^{\circ}}{\mathrm{RT}}\right]$

Pada persamaan 2, $R$ merupakan konstanta gas, $T$ merupakan temperatur absolut dan nilai 1000 merupakan konsentrasi air dalam satuan g. $\mathrm{L}^{-1}$.Nilai $K_{a d s}$ dan $\Delta G^{\circ}{ }_{a d s}$ yang diperoleh adalah 0,0324 dan $-3,75 \mathrm{~kJ} / \mathrm{mol}$ secara berturut-turut. Nilai $\Delta G^{\circ}$ ads bernilai negatif yang mengindikasikan bahwa adsorpsi inhibitor pada permukaan baja lunak adalah reaksi yang spontan. Menurut Atkins dan de Paula (2009), nilai $\Delta G^{\circ}$ ads yang berkisar $-20 \mathrm{~kJ} / \mathrm{mol}$ merupakan indikasi adanya interaksi elektrostatik antara molekul inhibitor yang bermuatan dengan logam bermuatan (Interaksi Van der Waals) atau dengan kata lain inhibitor WSC bekerja secara fisisorpsi pada permukaan baja lunak. Hal ini menguatkan hasil 
sebelumnya bahwa antara WSC dan permukaan baja lunak terjadi interaksi Van der Waals.

\section{Mekanisme Penghambatan Korosi WSC}

Inhibitor WSC dalam $\mathrm{HCl} 1 \mathrm{M}$ mengalami protonasi pada gugus fungsi yang berperan penting dalam penghambatan korosi pada baja lunak. Molekul WSC yang terprotonasi ini kemudian berkompetisi dengan ion hidrogen $\left(\mathrm{H}^{+}\right)$untuk teradsorpsi pada situs katodik di permukaan logam sehingga pembentukan gas Hidrogen $\left(\mathrm{H}_{2}\right)$ menjadi berkurang. Ion klorida $\left(\mathrm{Cl}^{-}\right)$dalam media petroleum sintetik dan $\mathrm{HCl} 1 \mathrm{M}$ bereaksi dengan bagian logam yang bermuatan positif di permukaan baja lunak dan membuat ion negatif lainnya berkumpul pada bagian antar muka antara elektroda dan media korosif, sehingga molekul WSC menjadi mudah untuk teradsorpsi pada situs anodik baja lunak. Mekanisme adsorpsi WSC terprotonasi pada permukaan baja lunak ditunjukkan pada Gambar 4.

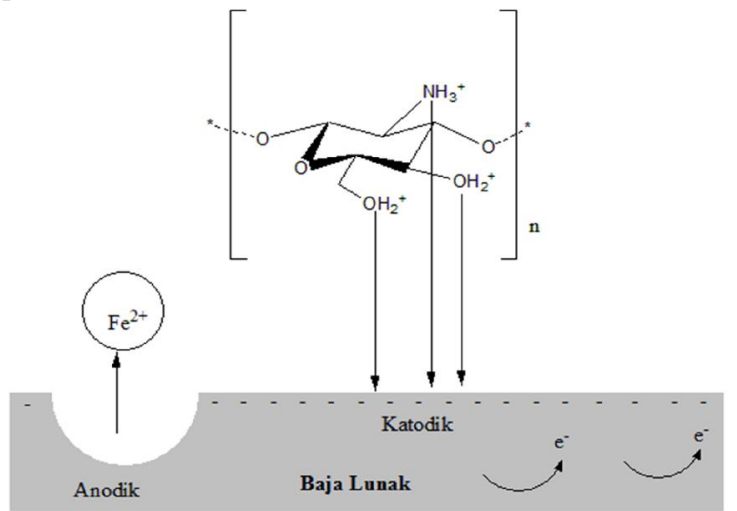

Gambar 4. Perkiraan interaksi elektrostatik antara WSC dengan permukaan baja lunak

Molekul netral diadsorpsi oleh baja lunak dengan mekanismepenggantian molekul air pada permukaan baja lunak [25].

\section{KESIMPULAN}

Kitosan larut air (water soluble chitosan, WSC) merupakan inhibitor ramah lingkungan yang baik dan cukup efisien untuk baja lunak dalam $\mathrm{HCl} 1 \mathrm{M}$. Evaluasi kinerja WSC dalam menghambat korosi pada baja lunak menunjukkan efisiensi inhibisi WSC meningkat terhadap konsentrasi dan mencapai efisensi maksimum pada konsentrasi $100 \mathrm{ppm}$. Efisiensi maksimum WSC dalam media $\mathrm{HCl} 1 \mathrm{M}$ diperoleh sebesar $73,50 \%$. Intepretasi hasil pengukuran dengan polarisasi potensiodinamik menunjukkan bahwa WSC merupakan inhibitor tipe campuran dan melindungi bagian anodik dan katodik baja lunak. Interaksi fisik antara baja lunak dan WSC dalam media $\mathrm{HCl} 1 \mathrm{M}$ dibuktikan dengan model adsorpsi isoterm WSC yang mengikuti model adsorpsi Freundlich.

\section{DAFTAR PUSTAKA}

[1] Knowles, P. R., Design of Structural Steelwork (Second), Glasgow; Surrey University Press, (1987).

[2] Negm, N. A., Kandile, N. G., Aiad, I. A., Mohammad, M. A., "New Eco-Friendly Cationic Surfactants: Synthesis, Characterization and Applicability as Corrosion Inhibitors for Carbon Steel in $1 \mathrm{~N} \mathrm{HCl",} \mathrm{Colloids} \mathrm{Surface} \mathrm{A} \mathrm{Physicochem,} 391$ (2011), 224.

[3] Davis, J. R., Corrosion: Understanding the Basics. Ohio; ASM International, (2000)

[4] Koch, G. H., Brongers, M. P. H., Thompson, N. G., Virmani, Y. P., Payer, J. H., Corrosion Cost and Preventive Startegies in the United States. Houston TX; NACE International, (2001).

[5] Oguzie, E. E., Wang, S. G., Wang, F. H., "Influence of Iron Microstructure on Corrosion Inhibitor Performance in Acidic Media", Journal of Physical Chemistry, 19 (2009), 8420.

[6] Dean Jr., S. W., Derby, R., Vondembussche, G. T., "Inhibitor Types", Material Performance, 20 (1981), 47.

[7] Gopal, J., Anjum, S., Sundaram, S., Prakash, R., "Musa paradisica Peel Extract as Green Corrosion Inhibitor for Mild Steel in $\mathrm{HCl}$ Solution", Corrosion Science, 90 (2015), 107-117.

[8] Restiawan, D., Harmami, "Kinina sebagai inhibitor korosi baja SS 304 dalam media $1 \mathrm{M} \mathrm{H}_{2} \mathrm{SO}_{4}$ dengan variasi suhu", Jurnal Sains dan Seni ITS, 2(2), 34-37, (2013)

[9] Mardhani, I., Harmami, "Pengaruh suhu terhadap korosi baja SS 304 dalam media $1 \mathrm{M} \mathrm{HCl}$ dengan adanya inhibitor Kinina", Jurnal Sains dan Seni ITS, 2(2), 76-78, (2013) 